\title{
Turismo de Aventura: conceitos e paradigmas fundamentais
}

\section{Adventure Tourism: fundamental concepts and paradigms}

\section{Victor López-Richard' Clever Ricardo Chináglia ${ }^{2}$}

RESUMO: O turismo de aventura foi examinado a partir da análise do comportamento e das motivações dos participantes. Os conceitos fundamentais relativos ao turismo de aventura foram expostos. Efeitos dos programas de aventura no processo cognitivo de participantes foram avaliados e discutidos a partir da confirmação empírica de paradigmas estabelecidos. As motivações e expectativas de clientes com diferentes perfis foram investigadas. A análise desses resultados indicou a necessidade de diferentes abordagens ao promover e organizar esses programas segundo o grupo a ser atingido. Foram indicadas as qualidades das experiências de aventura para o desenvolvimento de novas opções turísticas.

PALAVRAS-CHAVE: turismo de aventura; programas de aventura; motivações; expectativas.

ABSTRACT: Adventure tourism was examined by analyzing the participant behavior and motivation. Fundamental concepts related to the adventure tourism were exposed. Effects of adventure programs on the client cognitive process were evaluated and discussed using an empirical confirmation of

1. Doutor em Física. Membro do Centro Universitário de Montanhismo e Excursionismo; organizador de programas de aventura. Contato: Rua Vitório Giometti, 648 - 13564-330 - Sāo Carlos -sp; e-mail: vlopez@df.ufscar.br.

2. Mestre em Ciência e Engenharia de Materiais; especializaçāo em Ecoturismo. Fundador do Centro Universitário de Montanhismo e Excursionismo. Contato: Rua Viriato Fernandes Nunes, 236/ 142 - 13564-070 - Sāo Carlos - sP; e-mail: clever@ccdm.ufscar.br. 
previously established paradigms. Motivations, and expectations of participants with different profiles were surveyed. The analysis of the survey data recommended different approaches for promoting and organizing adventure programs, according to the group profile. Qualities of adventure experiences for developing new tourist options were indicated.

KEYWORDS: adventure tourism; adventure programs; motivations; expectations.

\section{Introdução}

O mercado do Turismo de Aventura - TA cresce no mundo e no Brasil em ritmo acelerado. $\mathrm{O}$ ecoturismo, que de certa maneira abrange as atividades relacionadas ao TA, cresce em taxas globais anuais de $10 \%$ a $30 \%$, e se comparadas aos $4 \%$ de crescimento do turismo em geral, tal modalidade aparece como um produto altamente promissor (Vincent e Thompson, 2002). Segundo dados da EMBRATUR (2002), “o crescimento do apelo turístico baseado na preservação e conservação da natureza (a fauna e a flora) [...] pelos países do primeiro mundo, coloca o Brasil na vanguarda como destino turístico nos próximos 10 anos". Porém, a escassez de estudos teóricos sobre as necessidades, motivações e expectativas de seus praticantes, bem como as dimensões do comportamento dentro do conceito do TA, podem obstruir seu adequado planejamento e afetar a tomada de decisões apropriadas sobre seu desenvolvimento.

Pode ser constatada a superposição de conceitos aplicados, muitas vezes de maneira incorreta, a uma ampla variedade de atividades ao ar livre: ecoturismo, turismo alternativo, esportes de aventura, esportes radicais etc. Essa confusão pode induzir a erros na avaliação do comportamento de consumo de participantes e na satisfação das demandas crescentes e mutáveis do mercado do TA.

Novas alternativas de lazer, esporte e recreação desenvolvidas na natureza crescem com rapidez, ajustando-se constantemente aos perfis e demandas dos clientes. Nesse processo, diferentemente do chamado turismo de massa, é gerado um ciclo de adaptação em que a interação do cliente com o meio ambiente modifica suas próprias perspectivas e exige uma adequação dos programas para ajustálos às novas motivações e expectativas. Por isso a importância de estudar adequadamente os conceitos que englobam atividades ao ar livre, e dentre eles, os conceitos relativos ao turismo desenvolvido em áreas naturais. Esse marco conceitual vai facilitar a compreensão de fenômenos associados ao comportamento dos indivíduos em programas de aventura, ressaltando o importante papel da motivação. A partir de coletas de dados sobre preferências de participantes em programas de aventura, será demonstrado como o perfil do participante pode ser determinante para os padrões de comportamento. A análise desses padrões ajudará a desvendar parte do processo de desenvolvimento cognitivo a que é submetido o indivíduo na experiência de aventura, além de indicar as possíveis distorçōes da simplificação holística das motivações e expectativas do complexo universo de participantes em programas de aventura.

\section{Revisão e introdução de conceitos}

Segundo Dawling (1997), podemos classificar o turismo como sendo de massa ou alternativo. No turismo de massa, encontraremos um número grande de pessoas procurando opções que repliquem, em boa medida, características da própria cultura em um cenário institucionalizado, com pouca interação cultural ou ambiental, com o cenário autêntico local. Já o chamado turismo alternativo, que representa a tendência de grandes e crescentes minorias, envolve a interação positiva e vantajosa do visitante com os valores naturais, culturais e comunitários locais. Nesse marco se enquadra o turismo natural englobando diferentes tipos de atividades em contato com a natureza.

O turismo natural pode ser subdividido, por sua vez, em turismo baseado na natureza, cujo principal objetivo é a observação e o TA (Dawling, 1997), em que o cliente estará envolvido em atividades altamente influenciadas pelas condições, às vezes imprevisíveis, do meio ambiente. $\mathrm{O}$ conceito de TA será definido posteriormente e nele focalizaremos nossa discussão.

Relacionado ao turismo natural aparece o conceito de ecoturismo contraposto ao de turismo convencional, em que os critérios de sustentabilidade do empreendimento são ressaltados. Nesse caso, a ênfase maior recai na ética da abordagem da atividade turística baseada na preservação do marco natural e comunitário no qual é concebida. Ceballos-Lascurain (1987: 14) define o ecoturismo como

viagem até áreas relativamente imperturbadas ou áreas naturais não contaminadas com o objetivo específico de estudar, admirar e desfrutar do cenário e de suas plantas e animais selvagens, assim como de qualquer manifestação cultural (ora do passado, ora atual) encontrada nestes locais.

Já a maioria dos autores invoca a educação ambiental, a conservação dos ecossistemas e da integridade da comunidade hospedeira como características fundamentais do empreendimento ecoturístico (Andersen, 1994; Buckley, 1994; 
Wight, 1993). Outros enfatizam seu caráter rústico e a tendência ao escape de rotinas urbanas (Backman et al., 1994; Williams, 1992). As inúmeras definiçōes existentes de ecoturismo mostram a notável influência do perfil ideológico dos seus formuladores.

No Brasil define-se ecoturismo como

segmento da atividade turística que utiliza, de forma sustentável, o patrimônio natural e cultural, incentiva a sua conservaçāo e busca a formação de uma consciência ambientalista através da interpretação do ambiente, promovendo o bem-estar das populações envolvidas (MICT/MA - Diretrizes para uma politica nacional de ecoturismo, 1995: 5).

De modo geral, o ecoturismo pode ser descrito com base no conceito de sustentabilidade, como sendo o turismo sustentável realizado em ambientes naturais (Chinaglia, 2002). Dessa forma, o ecoturismo deve ser a atividade turística que visa minimizar o impacto no meio ambiente no qual se desenvolve, priorizando a proteção e a conservação sustentável dos recursos ambientais (naturais, culturais, históricos etc.), bem como a contribuição para o bem-estar econômico e social da comunidade, resultado da interação e da coexistência harmoniosa entre esta e a atividade ecoturística.

Fica claro, assim, que o conceito de ecoturismo descreve uma abordagem ética que pode ser aplicada a diferentes formas de empreendimento, fundamentalmente àquelas que usam a natureza como marco, independentemente da atividade turística desenvolvida. Dada a generalidade dessa definição, existe o perigo de distorcê-la ao usá-la como estratégia de marketing ou ferramenta política. Esse é um problema a estudar e a encarar criticamente, mas não é o objetivo do presente trabalho.

De acordo com o abordado até o momento, fica claro que o TA é uma forma de turismo natural na qual os clientes participam com diferentes graus de envolvimento, em experiências de aventura que devem estar fundamentadas na ética do ecoturismo. Assim, para entender o conceito de TA, devemos indicar primeiramente em que consiste uma experiência de aventura.

A experiência de aventura pode ser descrita como experiência de lazer que, segundo Neulinger (1981), precisa ser um estado da mente, voluntária e intrinsecamente motivadora. Também deve envolver a percepção de risco, entendido como o potencial para perder alguma coisa de valor, que pode aparecer em diferentes graus de intensidade (Priest, 1992; Mitchell, 1983). O critério que faz de uma experiência, uma aventura, é o seu resultado incerto, portanto, arriscado, sempre associado a certo desafio.
Conforme indicam Fluker e Turner (2000: 380), uma aventura requer três elementos: "liberdade de escolha; gratificação intrínseca; e um elemento de incerteza, por exemplo, quando o resultado da experiência é desconhecido ou seus riscos são imprevisíveis". Assim, o elemento comum a qualquer definição de aventura como experiência é o risco. Ele deve influenciar as percepçōes individuais, portanto, os processos de tomada de decisōes e as motivaçōes.

Ao referir-se às atividades de aventura é comum o uso indistinto das denominaçōes esportes de aventura e esportes radicais para qualificar uma ampla variedade de eventos e atividades de lazer ou competição. Contudo, podemos tentar estabelecer um diferencial sutil entre elas, enfatizando, no caso dos esportes de aventura, a incerteza do resultado.

Os esportes de aventura nascem a partir da reprodução total ou parcial de experiências e técnicas expedicionárias em constante evolução: montanhismo, deslocamento por cordas fixas, canoagem, viagens de bicicleta etc. Em todas elas, os fatores naturais adicionam um importante elemento de incerteza, e o participante está intrinsecamente motivado pela sensação de desbravar, conhecer e encarar obstáculos imprevistos. Já os chamados esportes radicais englobam um grande número de atividades nas quais o desafio consiste em executar manobras de alta complexidade e vencer obstáculos - muitas vezes conhecidos de antemão - a partir de habilidades técnicas em modalidades esportivas nas quais fatores naturais imprevisíveis podem não influir no resultado.

Essas definiçōes não são normativas, pois ambos os conjuntos de atividades se interceptam e evoluem, interagindo continuamente, adaptando-se a novas e maiores exigências e habilidades dos participantes, mas podem ser úteis para a discussão que apresentamos. Segundo a EMBRATUR (apud Webventure, 2004), o turismo de aventura é

o segmento do mercado turístico que promove a prática de atividades de aventura e esporte recreacional em ambientes naturais e espaços urbanos ao ar livre, que envolvam emoções e riscos controlados, exigindo o uso de técnicas e equipamentos específicos, a adoçāo de procedimentos para garantir a segurança pessoal e de terceiros, e o respeito ao patrimônio ambiental e sociocultural.

De acordo com a definição citada anteriormente, é fato que a competência é um fator determinante em uma experiência de aventura, que consiste em uma combinação de conhecimentos, habilidades, comportamentos, atitudes, confiança e, muito importante, experiência pessoal. Para um programa de aventura ser realmente desafiador, será preciso sempre empenhar certa dose de competência pessoal ou coletiva para resolver as situaçōes de risco ou a incerteza do seu resultado. 
A relação entre o risco e a competência do participante, conhecida como paradigma da experiência de aventura (Priest, 1992), cria as condições do desafio que, segundo Martin e Priest (1986), podem ser classificadas em cinco diferentes graus: exploração e experimentação, aventura, aventura pico, desventura e devastação ou desastre.

Quando uma pessoa com alto nível de competência desenvolve uma atividade de baixo risco, o resultado é a condição de exploração ou experimentação. Se a competência diminuir ou o risco crescer, a experiência passa a ser uma aventura. O balanceamento desses componentes resulta na condição de aventura pico. Assim que o risco superar a competência, a experiência pode tender à desventura, e quando o risco é muito elevado ou a competência extremamente baixa, então pode ocorrer a devastação ou o desastre. $\mathrm{O}$ equilíbrio estará garantido pela correta percepção do risco envolvido na atividade, bem como pela adequada avaliação da competência pessoal para desafiá-lo.

A partir das características da experiência de aventura, fica claro que a principal tarefa para os organizadores de programas e roteiros de TA é adequar corretamente o nível de risco da atividade programada ao nível de competência do participante, a fim de garantir o grau máximo de estímulo. Considerando o caráter voluntário da experiência de aventura para constituir uma experiência de lazer, é importante também que seja facilitada a informação ao turista, para que este avalie o grau de risco a que será submetido e assim escolha o programa que melhor se adapta ao seu nível pessoal de competência. É claro que a maior responsabilidade na tomada de decisões recai sobre os organizadores, pois somente a experiência garante a correta avaliação desses fatores intangíveis, como demostraremos posteriormente.

Dessa forma, atividades realizadas dentro do TA podem, dependendo desse balanço entre riscos e competência do participante, requerer dos organizadores a utilização de guias especializados. Como exemplo citamos as atividades realizadas no meio ambiente natural por pessoas com pouca ou nenhuma experiência nesses locais. Essas atividades são muito comuns nas regiões de Brotas (SP) e em Bonito (MS). Nesses casos, a presença de um guia especializado, além de zelar pela segurança do praticante da atividade e garantir o componente da aventura, cuida também para que essa visitação não degrade o ambiente visitado. À medida que crescem a consciência sobre posturas eticamente corretas em relação ao meio ambiente e a experiência de se deslocar nesses locais, a presença de um guia pode ser dispensada. Exemplos desse tipo são as corridas de aventura, em que pequenos grupos encaram desafios de superar a si mesmos e aos demais grupos em um percurso determinado pelos organizadores da atividade, e sobre o qual somente tiveram conhecimento momentos antes do início da atividade.

\section{Motivações e expectativas}

O estudo dos fatores que determinam a motivação do turista para se envolver em programas de aventura é essencial para compreender tanto o seu comportamento quanto a segmentação de diferentes perfis de clientes, além da evolução de suas expectativas e necessidades. Ao compreender esses fatores, será possível sinalizar as tendências da procura e as adaptações requeridas do mercado e dos canais de comunicação para atingir diferentes tipos de público.

Em qualquer atividade humana, as motivações surgem a partir da necessidade de satisfazer certas carências. Nos programas de aventura não é diferente. $\mathrm{O}$ ser humano apresenta uma tendência de procura contínua por estímulos positivos (Ellis, 1973), que estão diretamente relacionados à produção de endorfinas como canalizadores fisiológicos das sensações de prazer, cuja intensidade varia de um indivíduo para outro. O estímulo, induzido pelo risco associado a certas atividades, pode desencadear emoções prazerosas. Esse risco, percebido pelo indivíduo, pode ser tanto objetivo, associado à taxa de acidentes de certa atividade, como subjetivo, isto é, percebido pelo participante mesmo sem tê-lo experimentado (Rossi e Cereatti, 1993).

Zukerman (1990) sugere que a procura por sensações e experiências variadas, desconhecidas e complexas, bem como o desejo de encarar riscos físicos e sociais, são produto do processo evolutivo. Como demonstraremos, testar a capacidade de vencer desafios e riscos potencializa o aprendizado e, conseqüentemente, induz a uma evolução.

O estímulo significativo e prazeroso proporcionado pela experiência de aventura, ao assumir riscos aparentes ou reais, pode induzir no indivíduo a necessidade de buscar sua reprodução, sem importar a motivação inicial que o levou a experimentá-lo. Este último elemento deve ser considerado ao avaliarmos a transformação da motivação do participante, sem prévia ou com pouca experiência, em comparação à daquele indivíduo mais experiente. Um exemplo que ilustra (desafortunadamente) bem essa relação é o comportamento do fumante. As motivações que levam o indivíduo a experimentar o cigarro podem ser variadas: imitar um padrão de comportamento, mostrar rebeldia, etc. Aqueles que continuarem a fumar cronicamente poderão sofrer adaptações de sua motivação, que pode resultar em aliviar o estresse emocional.

Mesmo que as necessidades a serem satisfeitas sejam comuns para um grande número de turistas - como fugir da pressão do trabalho semanal ou das rotinas urbanas -, as motivações podem resultar muito diferentes: experimentar o perigo, ficar com os amigos, aproximar-se da natureza etc. Esses serão os estímulos que farão o indivíduo optar por determinado destino turístico. Porém, um fator 
mais significativo a ser considerado na análise do comportamento do cliente é sua expectativa em relação ao serviço que será fornecido.

Os indivíduos possuem, invariavelmente, expectativas sobre os meios designados para satisfazer suas necessidades. No caso dos programas de aventura, elas também são numerosas: sentir medo, avistar animais selvagens, levar o corpo ao limite, aprender novas habilidades, entre outras. Sua confirmação, ou não, vai determinar o nível de satisfação do cliente com o serviço.

As expectativas são elementos altamente sensíveis e variáveis segundo o perfil do indivíduo, e podem sofrer modificações a partir de experiências anteriores em programas de aventura. É claro que a modificação das expectativas depende de vários fatores não relacionados à experiência prévia do indivíduo, tais como, por exemplo, a elevação da qualidade do equipamento, da infra-estrutura e das informações; o aumento da competência de guias e instrutores etc. Porém, será na base da familiaridade do cliente com a atividade em questão que este atualizará suas expectativas em maior ou menor grau (Fluker e Turner, 2000). É evidente que um indivíduo mais familiarizado com a atividade terá expectativas mais realistas, portanto, é esperado que sofra menos adaptações.

Segundo Schreyer e Roggenbuck (1978), variáveis demográficas, socioeconômicas e naturais têm pouca influência na explicação e predição das motivações dos participantes em atividades de lazer. A avaliação da satisfação ou não das expectativas depende fundamentalmente do processo de percepção, prévio e posterior, das características e qualidades do serviço. Isso explicaria, por exemplo, o declínio da procura por programas turísticos que não tenham conseguido se adaptar à evolução da percepção do indivíduo sobre a experiência de aventura em questão. Uma atenção maior aos níveis de confirmação das expectativas pode ajudar a manter ou a aumentar as taxas de retorno de clientes a determinadas atividades.

\section{Adaptação a partir da experiência}

Como indicamos anteriormente, o indivíduo submetido a uma experiência de aventura, além de satisfazer necessidades de estímulo, pode sofrer mudanças na percepção sobre a própria atividade. Demonstraremos como ocorre esse processo a partir de uma pesquisa de opinião realizada entre participantes iniciantes e experientes - de corridas de aventura.

As corridas de aventura são eventos em que se põe à prova a destreza de equipes em completar uma travessia desconhecida orientando-se com uma carta topográfica e uma bússola, deslocando-se por meio de diferentes modalidades de esportes de aventura (bicicleta de montanha, caminhada, canoagem, técnicas verticais etc.). Surgidas na Nova Zelândia em 1989, foram introduzidas no Brasil em 1998. Hoje, aparecem como programa oferecido por várias agências especializadas em TA, e cresce o número de adeptos. Ao envolver várias modalidades e atrair participantes com amplo perfil de idade e diferentes graus de experiência em programas de aventura, as corridas constituem um objeto adequado de estudo de tendências de comportamento e motivações.

Para medir as preferências de participantes em corridas de aventura e analisá-las em relação ao seu perfil, idade e experiência, foi elaborado um questionário sobre fatores relacionados a motivação e expectativas (ver Anexo). O questionário foi aplicado em uma população de participantes de corridas de aventura procedentes dos Estados de São Paulo, Rio de Janeiro e Paraná. O participante foi questionado sobre a ordem de preferência entre $\mathrm{n}_{\max }$ variáveis associadas a diferentes fatores motivacionais. Estas foram numeradas em ordem crescente segundo a menor preferência: $\mathrm{i}=1$ (maior preferência), $\mathrm{i}=\mathrm{n}_{\max }$ (menor preferência).

Para usar uma variável que indicasse, ao contrário da variável i, o grau de preferência em ordem crescente (quanto maior a preferência, maior seu valor), realizamos uma mudança de variáveis e normalizamos seu valor de maneira que a preferência máxima fosse sempre 1 e a mínima, 0 :

$$
\text { pref }=\frac{n_{\text {max }-i}}{n_{\max -1}}
$$

A escala da magnitude numérica da preferência foi padronizada para todos os fatores por meio dessa relação. É importante destacar que esses valores são relativos, apropriados para uma análise qualitativa. $\mathrm{O}$ questionário foi aplicado entre os dias 8 e 20 de dezembro de 2003 em uma lista de discussão sobre corridas de aventura na Internet, e durante um evento competitivo no Estado de São Paulo, em janeiro de 2004. Vinte e nove indivíduos responderam, sendo que 13 se definiram como experientes e 16 como iniciantes. Foi montada uma base de dados usando o programa EXCEL e para cada perfil de participante (experiente ou iniciante) foi calculado o valor médio da variável preferência (pref, na equação 1) para cada um dos fatores incluídos no questionário. 


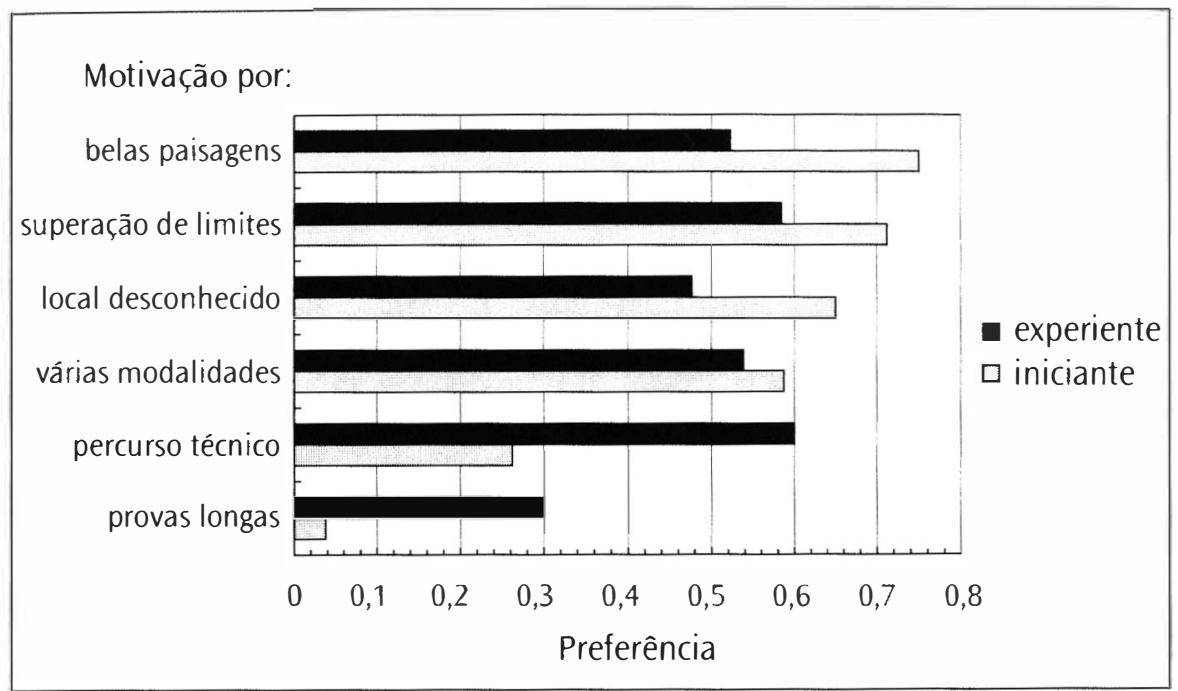

Figura 1 Motivações segundo o perfil (iniciante ou experiente)

A Figura 1 mostra o resultado da média das preferências por fatores associados às qualidades que motivam os participantes a se envolver em corridas de aventura. As qualidades dos locais dos percursos e a superação de limites são motivações importantes para a maioria dos competidores, independentemente do perfil. Porém, a discrepância da preferência por percursos técnicos (complexos) entre competidores iniciantes e experientes denota certa adaptação da motivação.

Um grau maior de mudança foi obtido na avaliação de preferências relativas às expectativas, como se observa nos gráficos apresentados nas Figuras 2 e 3 . A familiaridade com corridas de aventura torna preferíveis os temas associados à dificuldade técnica do percurso; já a pouca familiaridade com o evento parece gerar expectativas um pouco mais "românticas". Para compreender tais diferenças devemos mostrar as preferências relativas por modalidades para cada perfil de participante, que aparecem na Figura 4. As modalidades preferidas pela maioria dos participantes são aquelas associadas aos métodos tradicionais de expedição bicicleta (mountain-bike) e caminhada (trekking) -, porém, é significativa a preferência dos participantes experientes pela orientação. Ela é, sem dúvida, a modalidade mais técnica e complexa desse tipo de atividade.

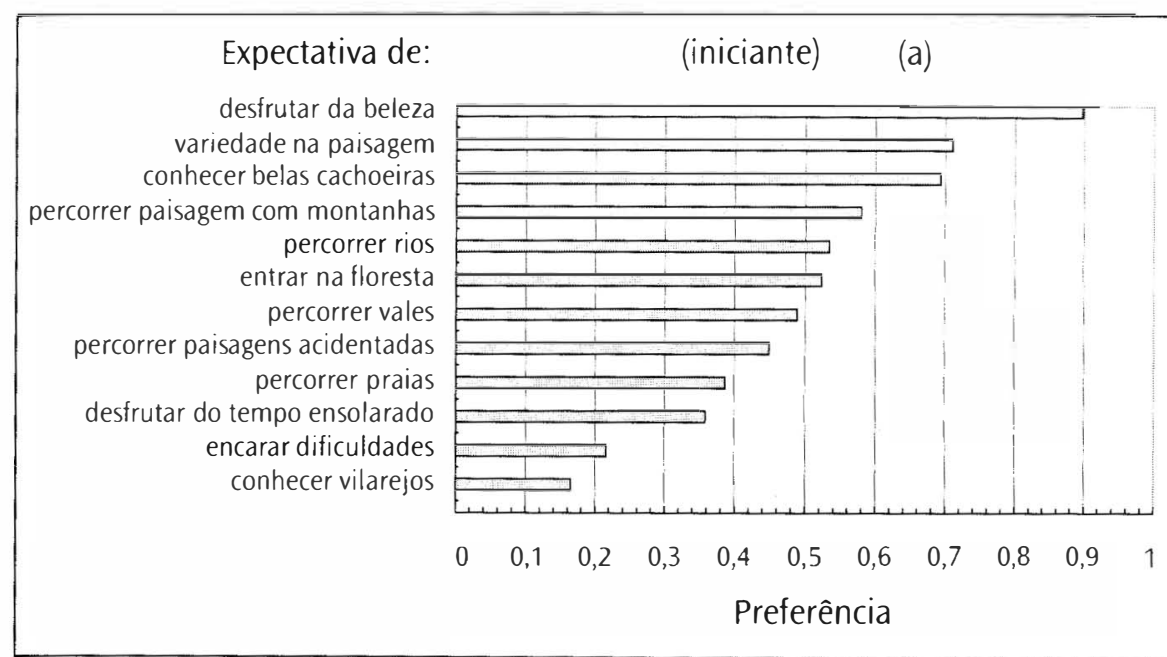

Figura 2 Expectativas médias dos participantes iniciantes

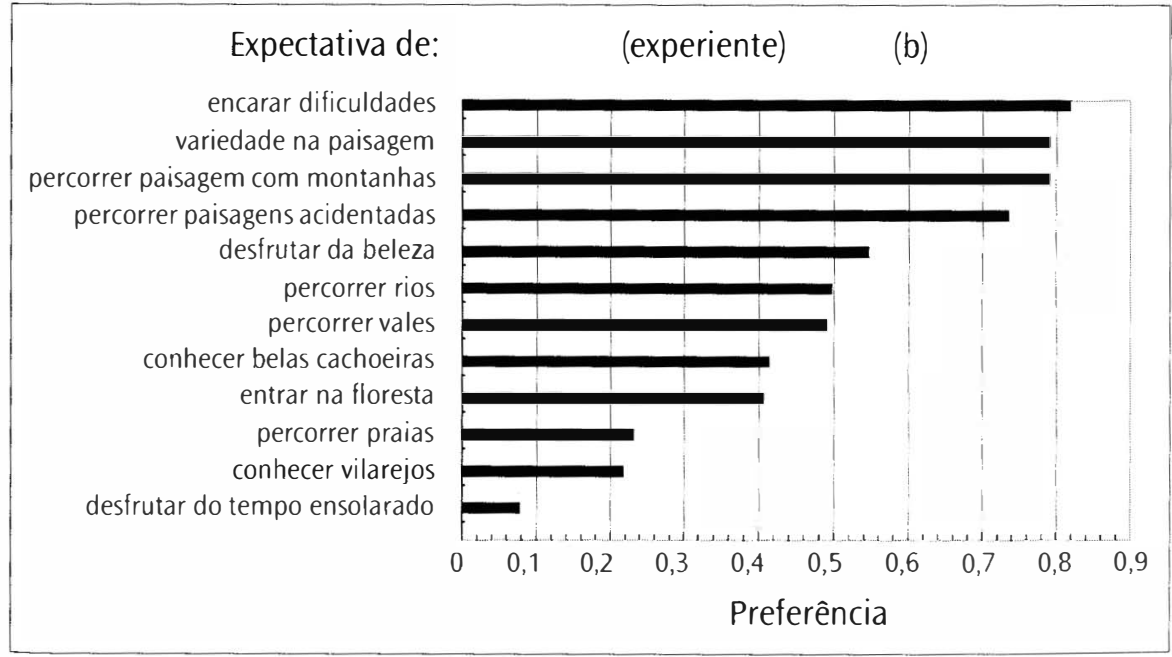

Figura 3 Expectativas médias dos participantes experientes 


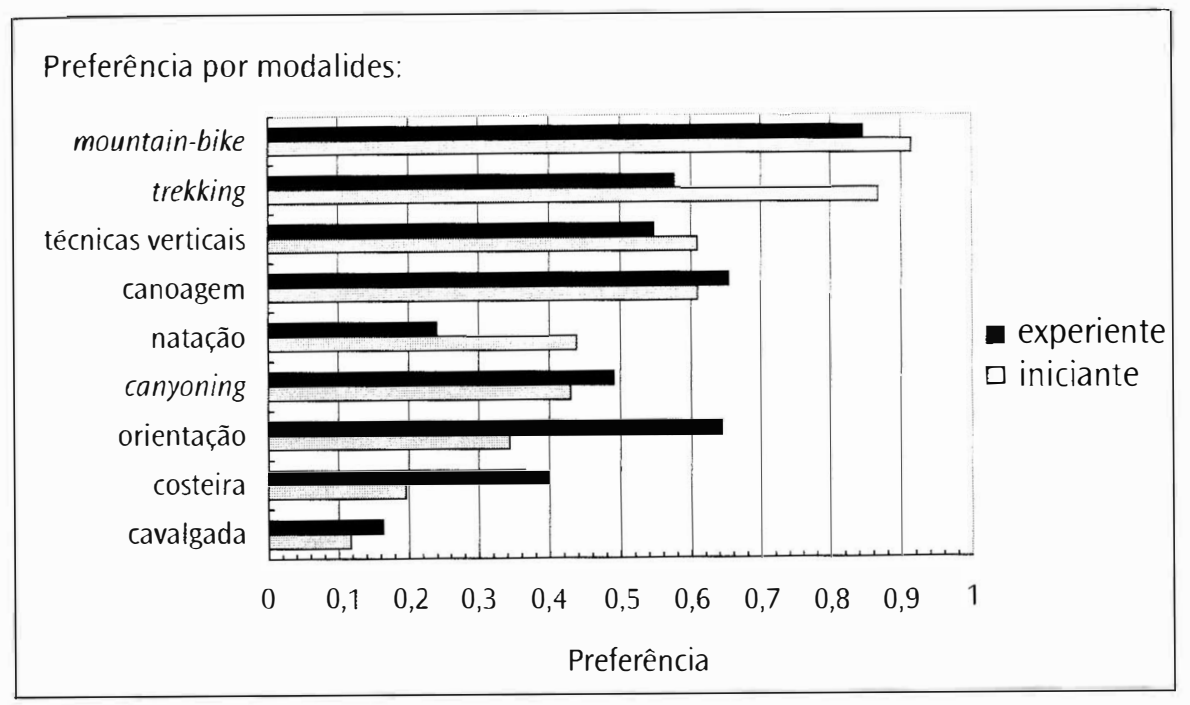

Figura 4 Modalidades em ordem crescente segundo a preferência média do participante iniciante

A divergência entre as expectativas de participantes com diferente perfil foi calculada como a diferença entre a preferência média do experiente e a preferência média do iniciante para cada um dos fatores avaliados:

$$
\text { DIVERGÊNCIA }=\text { pref }_{\text {experiente }}-\text { pref }_{\text {iniciante }}
$$

Dessa maneira, segundo mostra a Figura 5, quanto mais positiva é a divergência de uma determinada expectativa, mais preferida ela se torna pelo participante experiente; as divergências mais negativas, por sua vez, indicam preferências maiores por parte dos competidores iniciantes. O quadro das diferenças entre expectativas (Figura 5) corrobora o fato de a visão do participante iniciante mudar à medida que ele se familiariza com os desafios técnicos do evento. Detalhes do percurso, como a presença de cachoeiras, deixam de ser relevantes para o participante mais familiarizado com as dificuldades técnicas das provas. O experiente, a partir de uma percepção mais realista, é capaz de reconhecer na presença de florestas uma dificuldade, e não uma vantagem, pois a falta de referências visuais pode diminuir a capacidade de orientação; essa prioridade também o faz valorizar mais a paisagem acidentada e a presença de montanhas, que vão oferecer estruturas identificáveis que facilitem a orientação.

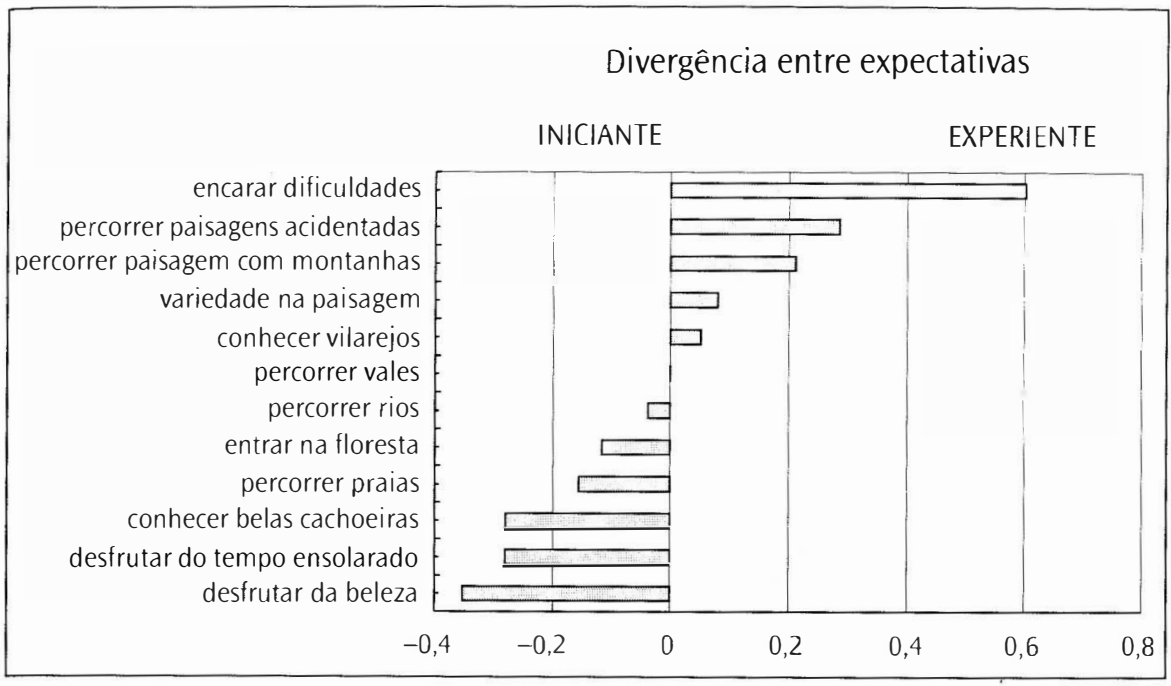

Figura 5 Diferença entre as expectativas dos participantes experientes e dos iniciantes, em ordem crescente

O processo de adaptação da competência do indivíduo para melhor avaliar os desafios técnicos de uma corrida de aventura, que acabamos de ilustrar, acontece de forma espontânea e pode ser reproduzido de maneira similar em outras experiências. Essa característica dos programas de aventura faz deles produtos extremamente versáteis, e deve ser considerada ao avaliar fatores motivacionais da participação de clientes com diferentes perfis.

\section{Benefícios e aplicações dos programas de aventura}

As experiências na área do TA têm um reconhecido potencial para fins exclusivamente recreativos ao fornecer oportunidades para revitalizar sensações e proporcionar emoçōes prazerosas. Mas tais programas têm muitas qualidades que podem ser exploradas com a finalidade de agregar valor a diferentes tipos de produtos turísticos, e para adaptar-se às diferentes necessidades e expectativas dos clientes.

Como demonstramos, as experiências de aventura são intrinsecamente motivadoras, assim, capazes de potencializar o aprendizado do indivíduo. $\mathrm{O}$ envolvimento emocional do participante na experiência ajuda a aguçar a atenção e 
o uso de todos os sentidos, o que facilita a assimilação de informações a partir da percepção real das causas e efeitos das ações. Dessa maneira, resulta mais fácil satisfazer as expectativas de clientes que anseiam pelo aprendizado de certas habilidades - isso sem precisar do uso abstrato de símbolos e recursos da memória. Nesse processo, as expectativas daqueles que não esperaram nenhum retorno em termos de conhecimento serão com certeza superadas.

A reavaliação de atitudes e da competência pessoal para vencer os desafios do programa; a facilitação de meios de comunicação interpessoal e do trabalho em equipe na solução de problemas; e a avaliação do comportamento sob uma nova perspectiva são características que podem ser canalizadas para fins de educação e treinamento. Muitas empresas usam essas qualidades das experiências de aventura para desenvolver programas de treinamento com seus executivos. Este produto aparece como opção comercial de várias agencias de TA e é conhecido pela sua designação em inglês: Outdoor Training. Finalidades terapêuticas de habilitação ou reabilitação também podem ser derivadas das experiências de aventura, pois estas têm o potencial de induzir mudanças comportamentais ao mostrar o impacto de comportamentos negativos e ao oferecer alternativas e espaço para a reflexão, ressaltando as qualidades positivas do indivíduo e a sua evolução a partir do aprendizado. Nesse caso, a experiĉncia de aventura será usada como referência metafórica de situações críticas da vida cotidiana.

A compreensão da relação entre os conceitos de risco percebido e de competência, de motivações e de expectativas, permite analisar o comportamento e as adaptações da percepção dos participantes em programas de aventura. As formas de adaptação e evolução do indivíduo a partir de experiências de aventura podem induzir a mudanças importantes nas motivações e nas expectativas de clientes. Uma análise desse processo pode indicar vias mais efetivas de comunicação para atingir o interesse do potencial participante e gerar programas que venham a satisfazer adequadamente suas necessidades em evolução. A tendência de ver o universo dos participantes de programas de aventura de forma homogênea pode distorcer a realidade e afetar o desempenho do empreendimento turístico voltado para essa atividade.

As experiências de aventura, ao envolver ativamente o cliente e suas emoções, constituem um espaço para o desenvolvimento de programas efetivos de educação, treinamento e terapia. Tais programas, se adequadamente concebidos, organizados e monitorados, podem transformar-se em produtos turísticos de alto valor agregado.

Anexo

\section{QUESTIONÁRIO APLICADO}

Este questionário faz parte de uma pesquisa sobre motivações e expectativas na participação em corridas de aventura.

Favor ler com atenção as opções das perguntas sobre preferências.

Obrigado pela sua colaboração.

- Idade

- Esportes convencionais que pratica e desde quando (ano)?

2. Você se considera um competidor de corridas de aventura: iniciante experiente

3. Numere em ordem de preferência $(1=$ mais preferida, $9=$ menos preferida) as modalidades seguintes de corridas de aventura:

$$
\begin{aligned}
& \text { trekking } \\
& \text { mountain-bike } \\
& \text { canoagem } \\
& \text { natação } \\
& \text { _ orientação } \\
& \text { canyoning } \\
& \text { técnicas verticais } \\
& \text { costeira } \\
& \text { cavalgada }
\end{aligned}
$$

4. Numere em ordem de preferência $(1=$ mais preferida, $6=$ menos preferida) as qualidades das corridas de aventura que motivam você a participar?

_ percurso técnico

belas paisagens

_ superação de limites varias modalidades

- local desconhecido _ provas longas 
5. Quais são suas expectativas ao participar de corridas de aventura? Numere em ordem de preferência ( 1 = mais preferida, $12=$ menos preferida $)$.

$\begin{array}{ll}\text { encarar dificuldades } & \text { percorrer vales } \\ \text { desfrutar da beleza } & \text { percorrer rios } \\ \text { entrar em florestas } & \ldots \\ \text { conhecer belas cachoeiras } & \text { variedade de paisagens } \\ \text { percorrer paisagens acidentadas } & \text { conhecer vilarejos } \\ \text { percorrer paisagens com montanhas } & \text { percorrer praias } \\ & \text { desfrutar o tempo } \\ & \text { ensolarado }\end{array}$

\section{Referências bibliográficas}

ANDERSEN, D. L. 1994. Developing ecotourism destinations: conservation from the beginning. Trends, v. 31, p. 31-38.

BACKMAN, K. F.; WRIGHT, B. A. \& BACKMAN, S. J. 1994. Ecotourism: a short descriptive exploration. Trends, v. 31, p. 23-27.

BUCKLEY, R. 1994. A framework for ecotourism. Annals of Tourism Research, v. 21, p. 661-669. CEBALLOS-LASCURAIN, H. 1987. The future of ecotourism. Mexico Journal, p. 13-14, jan.

CHINAGLIA, C. R. 2002. Desenvolvimento sustentável, educaçāo ambiental e ecoturismo: uma abordagem sistêmica. Prêmio SESC/SENAC de Turismo Sustentável. SENAC. Segunda colocação. A ser publicada pela Editora SENAC em conjunto com as demais obras premiadas.

DIRETRIZES para uma política nacional de ecoturismo. Disponível em: <http://www. ecobrasil.org.br/docs/EcoBrasil\%20AnxTecnico\%20\%20PoliticaNacionalEcoturismo \%20\%20мMA-мiCT\%20ago94.pdf>. Acesso em: abr. 2004.

DOWLING, R. K. 1997. Plans for the development of regional ecotourism: theory and practice. In: HALL, C. M.; JENKINS, J. \& KEARSLEY, G. (Eds.). Tourism planning and policy in Australia and New Zealand: cases, issues and practice. Sydney: McGraw-Hill. p. 110-134.

EMBRATUR, site oficial. Disponível em: <www.embratur.gov.br>. Acesso em: ago. 2002.

SOBRE os esportes - definições. Site da Webventure. Disponível em: <http://www.zone.com.br/ index.php?destino=imprensa_advfair $>$. Acesso em: abr. 2004.

ELLIS, M. J. 1973. Why people play. Englewood Cliffs, NJ: Prentice-Hall.

FLUKER, M. R. \& TURNER, L. W. 2000. Needs, motivations and expectations of commercial Whitewater rafting experience. Journal of Travel Research, v. 38, p. 380-389.

MARTIN, P. \& PRIEST, S. 1986. Understanding the adventure experience. Journal of Adventure Education, v. 3, p. 18-21.

MITCHELL, R. G. 1983. Mountain experience: the psychology and sociology of adventure. Chicago: University of Chicago Press.

NEULINGER, J. 1981. The physiology of leisure. Springfield, Illinois: Charles C. Thomas.
PRIEST, S. 1992. Factor exploration and confirmation for the dimensions of an adventure experience. Journal of Leisure Research, v. 24, p. 127-139.

ROSSI, B. \& CEREATTI, L. 1993. The sensation seeking in mountain athletes as assessed by Zukerman'ssensation seeking scale. International Journal of Sports Psychology, v. 24, p. 417-431. SCHREYER, R. \& ROGGENBUCK, J. W. 1978. The influence of experience expectations on crowding perceptions and social-psychological carry capacities. Leisure Sciences, v. 1, p. 373-394. VINCENT, V. C. \& THOMPSON, W. 2002. Assessing community support and sustainability for ecotourism development. Journal of Travel Research, v. 41, p. 153-160.

WIGHT, P. 1993. Ecotourism: ethics or eco-sell? Journal of Travel Research, v. 31, p. 3-9.

WILLIAMS, P. W. 1992. A local framework for ecotourism development. Western Wildlands, v. 18, p. 14-19.

ZUKERMAN, M. 1990. The psychophysiology of sensation seeking. Journal of Personality, v. 58, p. $313-345$

Recebido em 06/02/2004.

Aprovado em 07/05/2004 